Historic, archived document

Do not assume content reflects current scientific knowledge, policies, or practices. 



\title{
Two Plot Transfer Devices Developed For Aerial Photographic Forest Insect Trend Surveys
}

\author{
By R.C. Aldrich, ${ }^{1}$ Research Forester \\ Forest Insect Laboratory, Forest Service \\ U.S. Department of Agriculture, Beltsville, Md.
}

Aerial color photographic surveys, made periodically when insect feeding causes maximum tree foliage discoloration, offer promise as a means to record infestation changes from one such time to the next. A problem unique to this type of survey is the slow, tedious task of transferring locations of permanent trend plots from one set of photographs to the next. If the transfer is not accurate, the sometimes subtle change in the forest from one period to the next cannot be accurately determined. To aid photo-interpreters in making these transfers, two devices have been developed and tested as part of a current study to determine whether aerial color photography can be used to follow the trend of a balsam woolly aphid, Chermes piceae Ratz., infestation in Fraser fir, Abies fraseri (Pursh) Poir., near Mt. Mitchell, N.C. The purpose of this note is to describe these devices and how they function. They will be referred to as the "Old Delft" device and the "Ryker" device, ${ }^{2}$ thus identifying them with the stereoscope with which they are used.

\section{THE OLD DELFT DEVICE}

This device is made up of four components (fig. 1A) in addition to an Old Delft Scanning Stereoscope and a 16-tube fluorescent

\footnotetext{
1 The author wishes to thank John N. Sauls, Aircraft Mechanic, for his many helpful suggestions and assistance in fabricating these devices.

${ }^{2}$ Mention of commercial products does not imply endorsement by the U.S. Department of Agriculture, Forest Service.
}

\author{
U. S. DEPT. OF ACBPICIII TIIRE \\ NATIC." AGR'




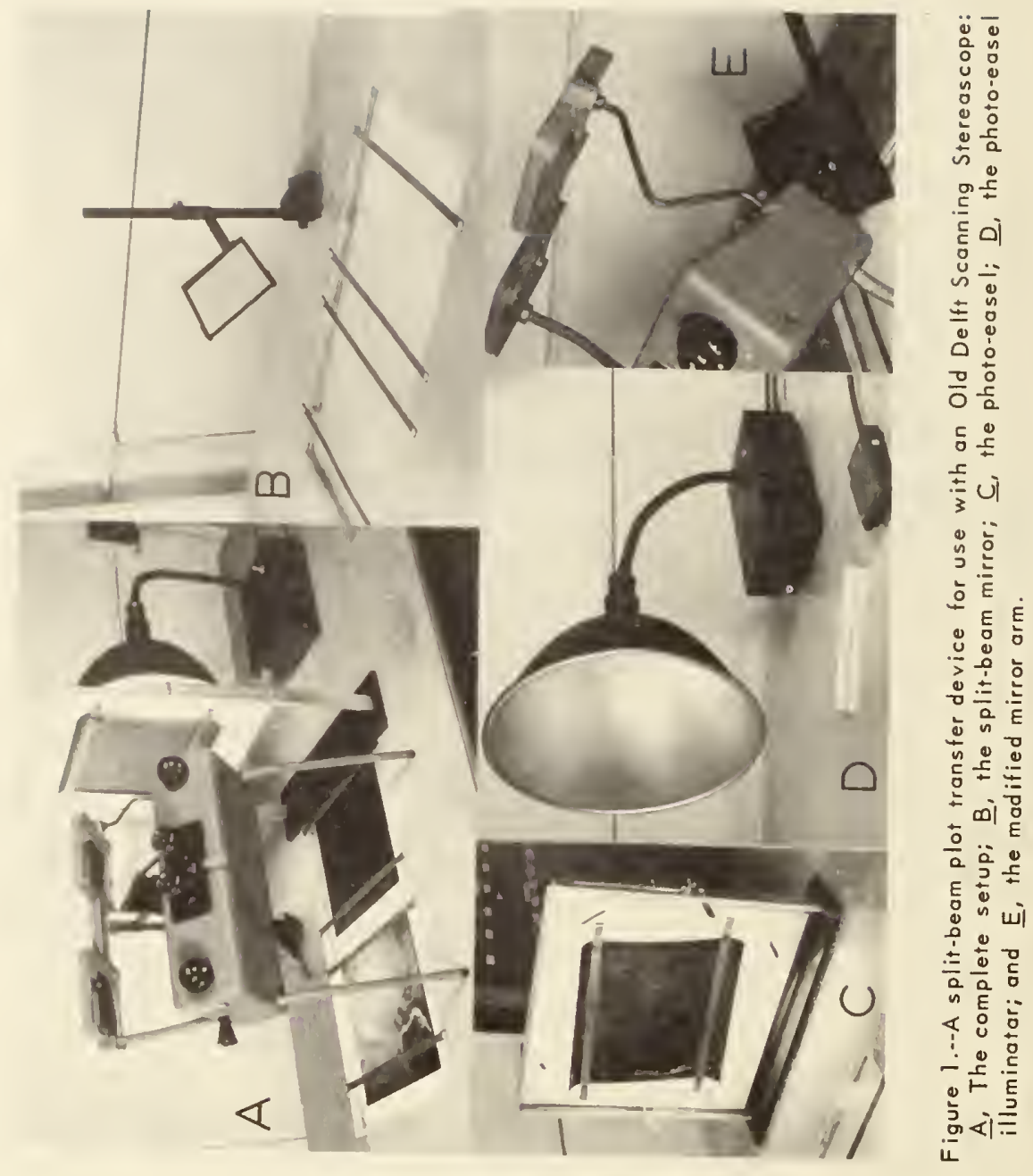


tabletop illuminator. Because the transparent mirror (fig. 1ㅡ) reverses images in reflection, the transparency is reversed when mounted on the opal plexiglas easel (fig. 1C) so that the image is viewed through the emulsion side rather than the base side of the film. This makes it possible to view the reflected photographic image in its correct orientation without impairing its quality. Figure 2, a functional diagram of the device, omits the Old Delft stereoscope in order to show other details more clearly. The dashed lines indicate the optical path through the stereoscope from eyepiece to transparencies.

Setting up the Old Delft device for use is relatively simple and can be accomplished in the following steps:

1. The new photography--a stereo-pair--to which a plot is to be transferred is mounted and oriented on the tabletop illuminator for normal viewing with the stereoscope.

2. The original transparency, on which the plot is located, is mounted on the upright easel with the emulsion side out (fig. $1 \underline{\mathrm{C}}$ ).

3. The easel is placed to the right of, and in line with, the transparencies mounted on the illuminator.

4. While looking through the ste reoscope, the transparent mirror is swung into position in the optical path of the right eye. (The stereoscope can be moved to the left or right so as to utilize a maximum area of the mirror without destroying the orientation of the transparencies already alined on the illuminator.)

5. The illuminator behind the easel is turned on by depressing the foot switch (fig. ID), thereby superimposing the details of the plot on the stereo-model under the stereoscope. The transferred plot will always be marked on the left-hand transparency of the stereo-pair, due to the position of the transparent mirror. (By reducing the amount of light under the right-hand transparency of the stereo-pair, the plot image on the original transparency will appear brighter, permitting better orientation with the plot image on the left-hand transparency.)

6. The superimposed images can be adjusted to the new transparencies by moving the easel in any of the four possible axes 


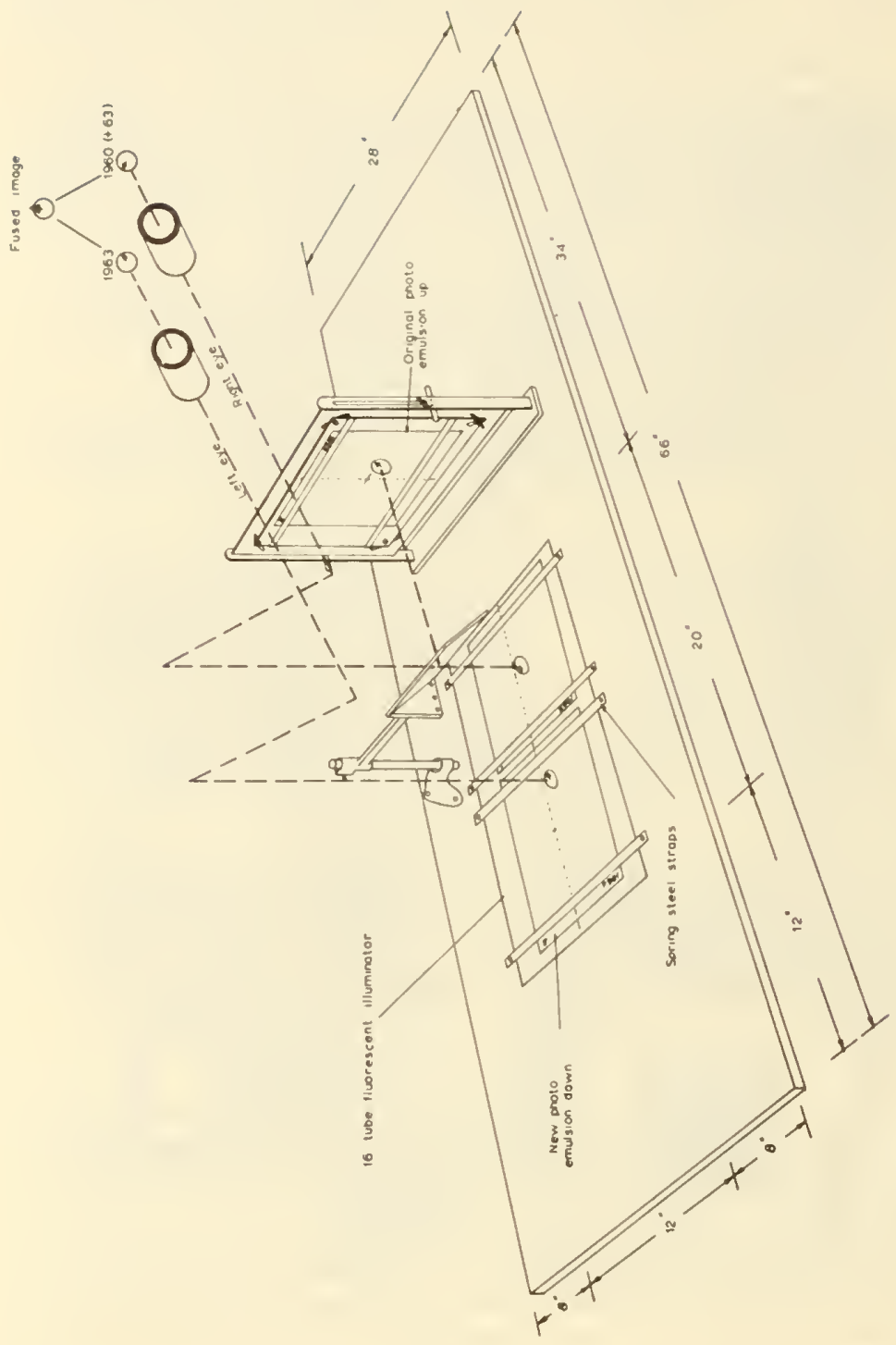

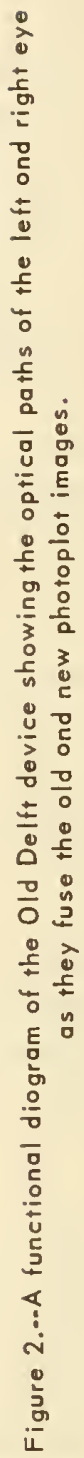


which remove the effects of scale, tilt, tip, or swing. Large differences in scale--up to 25 percent, for example--can be removed by raising the transparent mirror on its pedestal mount and at the same time raising the easel as in figure $1 \mathrm{~A}$. Because this caused the right-hand mirror arm on the stereoscope to interfere with the line of sight, a new arm was made that would bypass the mirror viewing area (fig. 1E). However, when the transparent mirror is raised to its highest point, images cannot be in focus at the same time. Under these conditions the transfer must be made without the aid of stereo, and the lights under the right-hand member of the stereo-pair must be turned off.

7. Blinking the light behind the easel aids greatly in getting images to coincide exactly.

8. Fine adjustments of the plot corner locations can be made individually by using the $\underline{X}$ and $\underline{Y}$ parallax controls on the stereoscope.

9. Corners of square or rectangular plots can be marked permanently on the left-hand transparency with the sharp point of a scribing tool.

An interpreter using the Old Delft device can transfer and interpret up to 50 plots per day. The principal advantages of this deyice over the Ryker are (1) transfers are made in three dimensions (when photo-scales are nearly the same), and (2) the transparent mirror can be swung away from the optical path. Thus, the plots located on the new photography can be interpreted without making a new setup.

\section{THE RYKER DEVICE}

The primary difference between the Ryker (fig. $3 \mathrm{~A}$ ) and the Old Delft device involves the stereoscope and its modifications. The Ryker mirror stereoscope, Model $M-11$, is mounted on an extended bracket, and a "Giant" erecting prism substituted for the right-hand mirror system (fig. 3B). The 16-tube fluorescent illuminator and the upright easel with rear illuminator and foot switch are the same for both devices. 

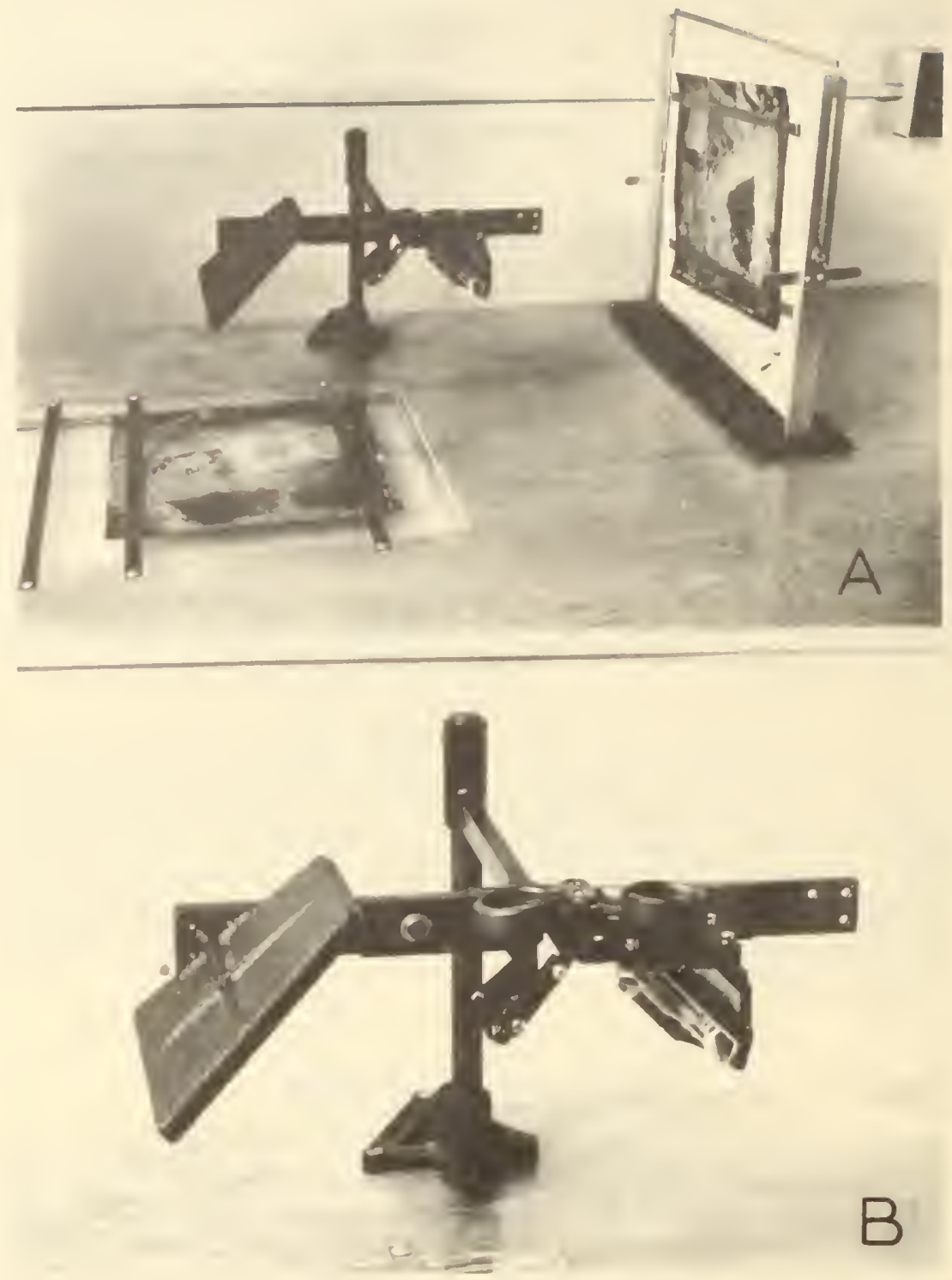

Figure 3.--A Ryker mirror stereoscope modified to make o plot tronsfer device: A, Eosel setup to use with block ond white prints; $\underline{B}$, the modified stereoscope. 
Figure 4 shows how the device works. Looking through the stereoscope, the interpreter alines the image of the new transparency, mounted on the illuminator under the left-hand mirror system, with the image of the original transparency, mounted on the upright easel. As shown in the diagram, the original is mounted with the base side out. This is because the Amici prism bends light rays $90^{\circ}$ and erects the image, instead of reversing the image like a mirror. The prism effect allows the device to be used with opaque prints, either color or black and white, and may make it suitable for other phototransfer work.

Adjusting the position of the photograph on the tabletop illuminator or the position of the easel will allow orientation of images within any portion of the area common to both photographs. Scale, tip, tilt, and swing can be adjusted by moving the easel in any of the four axes. The plot corners are transferred as described for the Old Delft device.

Using this equipment with color transparencies, 200 plots were transferred in a 5-day period. Unlike the Old Delft device, however, the new plot locations had to be interpreted as a separate operation. Thus, interpreting at a rate of 60 plots per day, $8 \frac{1}{2}$ days were required to do the work that was done in 5 days with the Old Delft device.

These two devices can be made in any shop equipped with the common types of metal-working tools. The materials are obtainable from sheet metal, electrical, and optical supply outlets at nominal cost. Drawings and material lists can be obtained on request from the Forest Insect Laboratory, Agricultural Research Center, Beltsville, Md. 


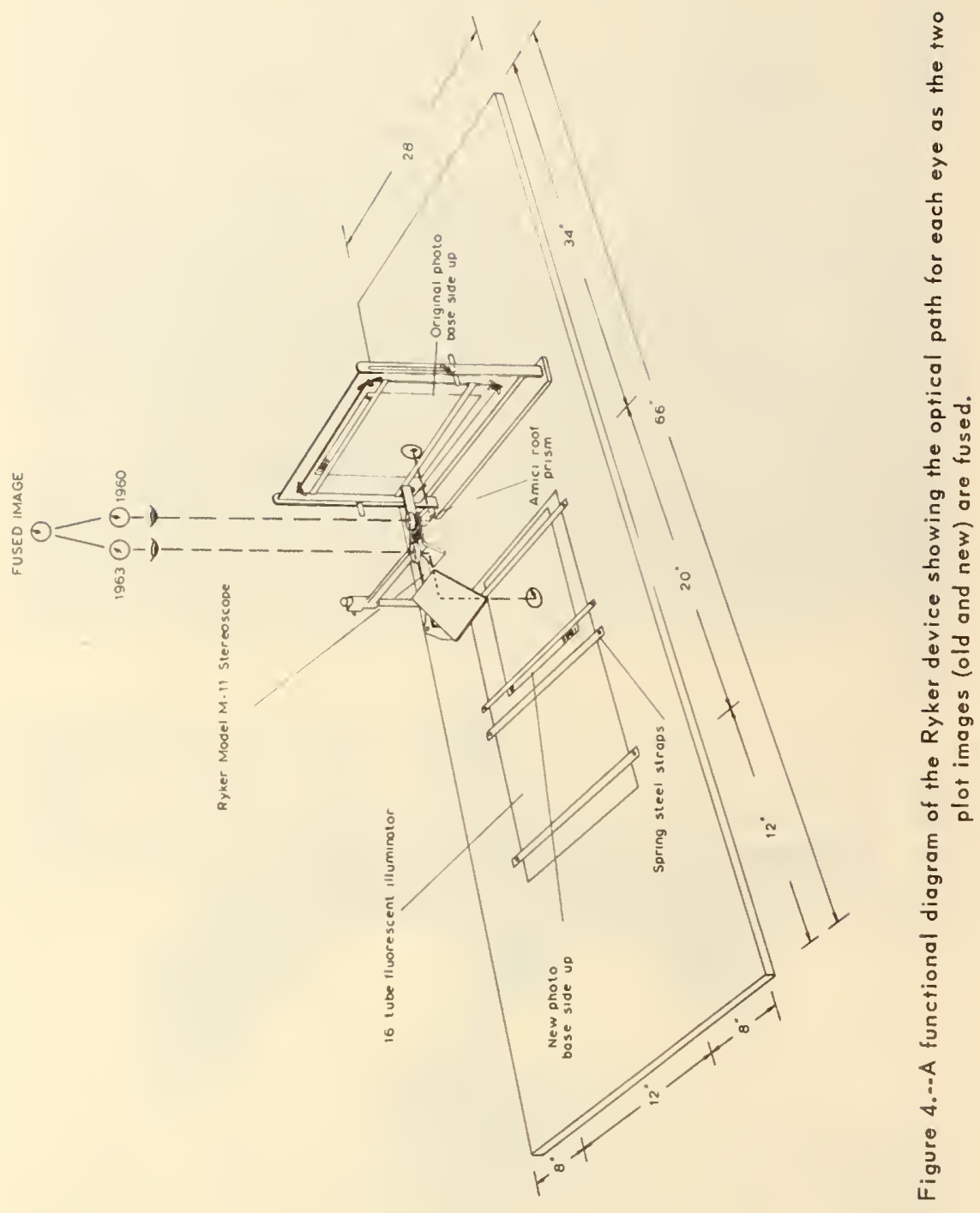

